\title{
The Quality of Primary Care Performance in Private Sector Facilities in Nairobi, Kenya: A Cross-Sectional Descriptive Survey
}

\author{
Gulnaz Mohamoud ( $\square$ mmgulnaz@yahoo.com ) \\ Aga Khan University \\ Robert Mash \\ Stellenbosch University
}

\section{Research Article}

Keywords: Primary health care, primary care, performance, quality, service delivery, accessibility, continuity, coordination, comprehensiveness.

Posted Date: September 30th, 2021

DOI: https://doi.org/10.21203/rs.3.rs-899530/v1

License: () (1) This work is licensed under a Creative Commons Attribution 4.0 International License. Read Full License 


\section{Abstract}

\section{Background}

Integrated health services with an emphasis on primary care are needed for effective primary health care and achievement of universal health coverage. The key elements of high quality primary care are first-contact access, continuity, comprehensiveness, coordination, and person-centredness. In Kenya, there is little information on these key elements and such information is needed to improve service delivery. This study aimed to evaluate the quality of primary care performance in a group of private sector clinics in Nairobi, Kenya.

\section{Methods}

A cross-sectional descriptive study adapted the Primary Care Assessment Tool for the Kenyan context and surveyed 412 systematically sampled primary care users, from 13 PC clinics. Data was analysed to measure 11 domains of primary care performance and two aggregated primary care scores using the Statistical Package for Social Sciences.

\section{Results}

Mean primary care score was $2.64(S D=0.23)$ and the mean expanded primary care score was $2.68(S D=0.19)$, implying poor overall performance. The domains of first contact-utilisation, coordination (information system), family-centredness and cultural competence had mean scores of $\geq 3.0$ (acceptable to good performance). The domains of first contact (access), coordination, comprehensiveness (provided and available), ongoing care and communityorientation had mean scores of $<3.0$ (poor performance). Older respondents $(p=0.05)$ and those with higher affiliation to the clinics $(p=0.01)$ were more likely to rate primary care as acceptable to good.

\section{Conclusion}

These primary care clinics in Nairobi had a poor overall performance. There was a report of acceptable-to-good performance in first-contact utilisation, the information systems, family centredness and cultural competence. However, patients rated first-contact access, ongoing care, coordination of care, comprehensiveness of services, community orientation and availability of a complete primary health care team, as poor. Performance could be improved by deploying family physicians, increasing the scope of practice to become more comprehensive, improving access after-hours and marketing the use of the clinics to the practice population.

\section{Introduction}

Primary health care (PHC) drives progress towards health care for everyone and is the foundation of any health care system.(1)(2) Strengthening PHC is therefore crucial and more important than ever before.(1) The Astana declaration, signed in 2018, emphasised that health services should be integrated, cost-effective, available, accessible, comprehensive and of high quality.(3)(4) The World Health Assembly (2019) realised the role of PHC in achieving universal health coverage (UHC).(5) However, due to weaknesses in PHC systems, several gaps exist in providing high quality, comprehensive and personcentred care, especially in low-and middle-income countries (LMIC).(5) A review of best practices to decide on health system responses, highlighted the importance of reforms aimed at improving accessibility and providing quality related to the model of service delivery as well as integrating the services.(3)

It is acknowledged that countries exhibiting strong and efficient PHC systems have better health outcomes with fewer hospital admissions.(6)(7) This is achieved when health promotion and disease prevention is balanced with treatment and resources are directed to PHC.(6)(7)(8) However, many LMICs in Africa have not implemented effective PHC despite their political commitment.(9)

The World Health Organization (WHO) has identified three levers to improve PHC: multi-sectoral policy and action, empowered people and communities, and integrated health care services with emphasis on primary care and essential functions of public health.(10) Primary care (PC) is defined as a "key process in the health system that supports first-contact, accessible, continued, comprehensive and coordinated patient-focused care" and acts as gatekeeper to other levels of care.(10)(11)

Primary care in sub-Saharan Africa (SSA) faces difficulties such as hospital-centred priorities, health care fragmentation by vertical programmes, resource limitations and misappropriated priorities, the burdens of communicable and non-communicable diseases, and reliance on low level and sometimes inadequately trained health care providers.(1)(12)(13) However, PC is still the main point of entry for most people seeking health care, and yet, PC in Africa lacks the ability to provide high quality care.(12)(14) The key elements of high quality service delivery are easy access for people with health problems, continuity, comprehensiveness, coordination, along with the attributes of family and community-oriented care delivered in a person-centred manner.(15) Therefore, a comprehensive, horizontally integrated, person-centred, community-based, high quality PC approach is needed in the era of emerging health challenges such as the coronavirus pandemic in order to achieve the goals of UHC.(3)(16)(17)(18)

In Kenya, numerous efforts have been made to achieve UHC by increasing access and utilisation through the introduction of free PC and maternity services as well as health insurance subsidies.(19)(20) However, despite the increase in utilisation and broader coverage of the population, the quality of PC services remains challenging in Kenya and other African countries.(19)(20)(21)(22)(23) Achieving the goal of UHC also requires evaluating the quality of PC and improving the key dimensions of comprehensiveness, accessibility, continuity, coordination and person-centredness.(16) These key dimensions are also highlighted by the PHC Performance Initiative, Primary Care Assessment Tool by Starfield and systematic reviews as what needs to be measured.(15) (24)(25)(26) The quality of PC is important in both public and private sectors and the quality of service delivery needs to be measured.(15)(27) The 
evaluation of PC would facilitate understanding and lead the strengthening of service delivery in PC.(28) A study carried out in China recommended evaluation and accountability of the performance to encourage high-quality and high-value care in the delivery of PC.(29) However in SSA a void exists in the available information on the quality and performance of PC.(28) The absence of such information impedes the ability of policymakers and implementers to identify areas that need improvement as well as prioritise the use of resources.(15) Improvement in PC service delivery will lead to greater health outcomes, equity, efficiency, responsiveness and resilience of the health system.(15)(28)(30)

In Kenya, clinical officers (mid-level practitioners) offer most of the PC services in the public and in some private care facilities, whilst general practitioners (doctors) offer services mostly in the private sector, although the majority do not have specialist postgraduate training.(31) Specialist training in family medicine is available, (32)(33)(34) (35) but the number of family physicians in Kenya is very limited.(36) Furthermore, Kenya is no different in having limited data and information on the performance of PC.(15)(19)

Governments typically focus their attention on the quality of public sector services and the measurement of quality in the private sector may be even more neglected. Private sector PC is also varied and diverse in terms of geographical location, types of practice and organisation, which makes measurement of quality complex and difficult.(37) Measurement needs to take into account the entire process of care from the perspective of the patient.(27) No previous study in Kenya has evaluated the key dimensions of PC performance in service delivery. This study aimed to evaluate the users' experience of PC in accessibility, comprehensiveness, continuity, coordination, community-orientation as well as aspects of person-centredness in a group of private sector PC clinics in Nairobi. Gaps in desired performance could be identified to inform tailored interventions for improvement.

\section{Methods}

\section{Aim}

The quality of primary care performance in private sector facilities in Nairobi, Kenya: A cross-sectional descriptive survey.

\section{Study design}

This was a cross-sectional descriptive survey of patients in primary care using the Kenyan Primary Care Assessment Tool (KE-PCAT).

\section{Setting}

This study was carried out in 13 primary care clinics within the city of Nairobi, run by general practitioners (GPs). All the clinics were operated by a private health care organisation, affiliated with a tertiary care referral hospital. These were ambulatory primary care clinics, offering services to all age groups in urban, semi-urban and peri-urban areas of Nairobi. The clinic staff included receptionists, registered nurses, laboratory technicians, radiographers and pharmacy technicians. The electronic medical record system allowed access to the patients' records at any of the clinics associated with this organisation. The clinics provided promotive, preventative and curative services for all age groups. They had a dispensing pharmacy, laboratory and offered referral services to the specialists' clinics (including family medicine) at the tertiary hospital. The patients came from diverse socio-economic backgrounds and most had private medical insurance by virtue of their employment. Previous studies at the same clinics showed that most of the patients spoke English and well educated.(38)(39)

\section{Study population and sample size}

The study population included patients aged 18 years and above at the 13 primary care clinics. These patients should have attended the same clinic at least three times prior as they were required to have experienced the care provided.(23) Those who did not provide consent or the number of visits were less than 3 were excluded from the study. All patients below eighteen years of age were also excluded.

These primary care clinics served approximately 15275 patients on a monthly basis. Therefore, the sample size calculation was based on a population of 20,000 patients, since calculations for the sample size do not change markedly in populations over 20,000 . The calculation was based on an expected proportion of $61 \%$ of users having a good primary care score (score $\geq 3)(40)$, a $5 \%$ margin of error and $95 \%$ confidence interval. Sample size was calculated using Fischer's formula that gave a figure of 375 , and after adjusting for $10 \%$ of incomplete response, the minimum sample size required was 412 .

\section{Sampling strategy}

The sample size of 412 was distributed amongst the 13 clinics proportional to the monthly workload. Patients that met the inclusion criteria were systematically sampled at each clinic until the sample size was achieved. If the patient did not provide consent, the next consenting patient was selected as per the systematic approach to sampling.

\section{Data collection tool}

The Primary Care Assessment Tool (PCAT) was originally developed by Barbara Starfield et al. at the Johns Hopkins Populations Care Policy Centre for underserved populations in USA.(26)(41) It was cross-culturally validated and first adapted for the African context in South Africa.(23)

The PCAT enables an evaluation of PC performance in terms of access, comprehensiveness, continuity, coordination, community orientation, familycentredness, cultural competence and the primary health care team.(23)(42)

The short user's version of the South African PCAT (ZA-PCAT) was validated and adapted for the Kenyan PC context (KE-PCAT). The heads of the Departments of Family Medicine of the five academic institutions in Kenya and their senior faculty, who understood the key principles of PC and the 
Kenyan context, participated in the validation process. The content of the tool was reviewed by the panel that also included the principal investigator. The reviewers ensured that the questions were relevant and appropriate for the Kenyan context, while preserving the integrity of the tool.

The panel achieved consensus ( $\geq 70 \%$ of panel) on the content of the domains and items of the PCAT. From an original of 97 questions, two items were excluded as they were not relevant to the Kenyan context. Items requiring rephrasing for the local context were identified and the demographic section was adapted, taking into consideration the local socio-economic conditions and terms.

The revised tool was then assessed for feasibility and understanding through a pilot study, carried out at a PC clinic belonging to the same organisation, outside the Nairobi County, that did not comprise as a part of the main study.

Data was collected on 11 domains as shown in Table 1. In addition, data on the extent of affiliation to the PC clinics, self-reported health assessments and socio-demographic information was collected. Most items were measured using a 4-point Likert scale from 1 (definitely not), 2 (probably not), 3 (probably) and 4 (definitely). There was also the option 'not sure, or don't remember'.

Table 1

Domains, items and definitions for the PCAT.(13)

\begin{tabular}{|c|c|c|}
\hline Domains & $\begin{array}{l}\text { Number } \\
\text { of } \\
\text { items }\end{array}$ & Definition \\
\hline $\begin{array}{l}\text { 1. First contact } \\
\text { (access) }\end{array}$ & 5 & $\begin{array}{l}\text { The provision of primary care services that are accessible when a need for care arises. First contact refers to the } \\
\text { primary care provider being responsible for assisting the client to enter the healthcare system for each non-referred } \\
\text { provision of health care. }\end{array}$ \\
\hline $\begin{array}{l}\text { 2. First contact } \\
\text { (utilisation) }\end{array}$ & 3 & $\begin{array}{l}\text { The utilisation of primary care services when a need for care arises. First contact refers to the primary care provider } \\
\text { being responsible for assisting the client to enter the healthcare system for each non-referred provision of health } \\
\text { care. }\end{array}$ \\
\hline 3. Ongoing care & 9 & $\begin{array}{l}\text { The use of a regular source of care over time that is not limited to certain types of healthcare needs. Longitudinally } \\
\text { involves the development of a patient-provider relationship based on established trust and a knowledge of the } \\
\text { patient and his/her family. A 'health care home' is thus established for each patient to promote the provision of } \\
\text { ongoing care regardless of the presence or absence of disease. }\end{array}$ \\
\hline $\begin{array}{l}\text { 4. Coordination } \\
\text { (system) }\end{array}$ & 10 & $\begin{array}{l}\text { Linking of healthcare events and services. Primary care has the responsibility and obligation to transfer information } \\
\text { to and receive it from other resources that may be involved in the care of a client, and to develop and implement an } \\
\text { appropriate plan for healthcare management and disease prevention. }\end{array}$ \\
\hline $\begin{array}{l}\text { 5. Coordination } \\
\text { (information) }\end{array}$ & 3 & $\begin{array}{l}\text { Coordination requires the establishment of mechanisms to communicate information and the incorporation of that } \\
\text { information into the client's plan of care. }\end{array}$ \\
\hline $\begin{array}{l}6 . \\
\text { Comprehensiveness } \\
\text { (available) }\end{array}$ & 21 & $\begin{array}{l}\text { Primary care makes available a range of essential personal health services that promote and preserve health and } \\
\text { provide care for illness and disability. }\end{array}$ \\
\hline $\begin{array}{l}7 . \\
\text { Comprehensiveness } \\
\text { (provided) }\end{array}$ & 9 & $\begin{array}{l}\text { Primary care offers a range of essential personal health services that promote and preserve health and provide care } \\
\text { for illness and disability. }\end{array}$ \\
\hline $\begin{array}{l}\text { 8. Family- } \\
\text { centredness }\end{array}$ & 3 & $\begin{array}{l}\text { Care understands the impact of family characteristics on the genesis and prevention of ill health, as well as the } \\
\text { response to both medical and psychosocial interventions. Family-centred primary care recognises and incorporates } \\
\text { knowledge of the family context (resources, risk factors, social factors) into the planning and delivery of primary } \\
\text { care. }\end{array}$ \\
\hline $\begin{array}{l}\text { 9. Community } \\
\text { orientation }\end{array}$ & 6 & $\begin{array}{l}\text { Care refers to efforts to recognise the primary care needs of a defined population. The effective delivery of services } \\
\text { to individuals and communities is based on an understanding of community needs and the integration of a } \\
\text { population perspective in the provision of health care. Primary care }\end{array}$ \\
\hline & & providers contribute to and participate in community assessment, health surveillance, monitoring, \\
\hline & & and evaluation. \\
\hline $\begin{array}{l}\text { 10. Culturally } \\
\text { competent }\end{array}$ & 5 & $\begin{array}{l}\text { Care incorporates cultural references into the provision of primary care. Services are designed to be acceptable to } \\
\text { people in the community, who may be distinguished by common values, language, heritage, and beliefs about health } \\
\text { and disease. The views of these groups should be determined and incorporated into decisions involving policies, } \\
\text { priorities, and plans related to the delivery of }\end{array}$ \\
\hline & & healthcare services. \\
\hline $\begin{array}{l}\text { 11. PHC team } \\
\text { available }\end{array}$ & 6 & $\begin{array}{l}\text { The availability of members of the multidisciplinary primary health care team such as social workers, therapists or } \\
\text { community health workers. }\end{array}$ \\
\hline $\begin{array}{l}\text { 12. Primary care } \\
\text { score }\end{array}$ & (Total) & $\begin{array}{l}\text { Mean of the scores for: first contact (utilization); first contact (access); extent of affiliation with a place/doctor; } \\
\text { ongoing care; coordination; coordination (information); comprehensiveness (services available); comprehensiveness } \\
\text { (services provided). }\end{array}$ \\
\hline
\end{tabular}

Source: Evaluating the performance of South African primary care: a cross-sectional descriptive survey.(13) 


\section{Data collection process}

After the patients were registered at the reception and before the triage process, the research assistant approached every third patient from the register. Those that consented, were asked about the number of times they had visited this facility. The participants who met the inclusion criteria were briefed about the study by the research assistant and those who agreed to participate were requested to give written consent. Research assistants administered the questionnaire in a private room. The interviews were conducted in English and minor clarification was provided where needed in Kiswahili. Research assistants were trained according to the PCAT training manual and were fluent in both official languages of Kenya, English and Kiswahili.(43) Data quality was checked by the principal investigator at the clinic, before entering into MS Excel for further analysis.

\section{Data analysis}

Performance of the data analysis was according to the PCAT manual. The data was analysed by the first author using the Statistical Package for Social Sciences (SPSS) version 25.

A mean score was calculated for each domain from the associated items using the Likert scale from $1-4$. Some items were reverse scored prior to the calculation as per the PCAT manual. In addition, a binary variable was constructed, where a mean score $\geq 3$ was seen as 'acceptable to good performance' and $<3$ as 'poor performance'.

To calculate affiliation with the PC clinics, users were first asked about the usual place or person where they sought care. They were then asked to identify any alternative place or person that they regularly visited and which place knew them best. The user's extent of affiliation with the PC clinics was categorised into "high" for those who only attended the PC clinic in the study, "moderate" for those users that sometimes attended another place, but were known best at the study site, and "low" for users that sometimes attended another place and were also known best at the alternative place.

The PC score was calculated as the mean of the domain scores for affiliation, first contact (utilisation), first contact (access), ongoing care, comprehensiveness (services available), and comprehensiveness (services provided). The expanded PC score also included the domains of familycentredness, community orientation, cultural competence and the primary health care team.

Continuous variables were summarised using means and standard deviations (SD) or medians and inter-quartile ranges (IQR), depending on the distribution of the data. Categorical data was summarised using frequency counts with the corresponding percentages. Chi-square test compared the domains and socio-demographic variables with the PC score, when the data was categorical. When necessary post hoc analysis of the chi square test was performed.

\section{Results}

The KE-PCAT was administered to 412 participants (Table 2). The majority were female (55.1\%) and the median age of the users was 34.0 (IQR: $28.0-$ 42.0). Figure 1 shows the age distribution of the participants. Most of the participants were in full time employment (58.7\%), university graduates (73.5\%) and living in permanent dwellings (99.3\%). The users' extent of affiliation with the PC facility was seen as "high" in 249 (60.4\%), "moderate" in 95 (23.1\%) and "low" in 65 (15.8\%). 
Table 2

User characteristics ( $\mathrm{N}=412)$

\begin{tabular}{|c|c|c|}
\hline Variables & $\mathbf{N}$ & $\%$ \\
\hline \multicolumn{3}{|l|}{ Gender } \\
\hline Male & 185 & 44.9 \\
\hline Female & 227 & 55.1 \\
\hline \multicolumn{3}{|l|}{ Age group (years) } \\
\hline $20-29$ & 107 & 26.0 \\
\hline $30-39$ & 176 & 42.7 \\
\hline $40-49$ & 86 & 20.9 \\
\hline $50-59$ & 37 & 9.0 \\
\hline $60-69$ & 6 & 1.5 \\
\hline \multicolumn{3}{|l|}{ Preferred language } \\
\hline English & 219 & 53.2 \\
\hline Kiswahili & 186 & 45.1 \\
\hline Others & 6 & 1.5 \\
\hline Refuse to answer & 1 & 0.2 \\
\hline \multicolumn{3}{|l|}{ Employment } \\
\hline Employed-full time & 242 & 58.7 \\
\hline Employed-part time & 59 & 14.3 \\
\hline $\begin{array}{l}\text { Self-employed } \\
\text { (informal sector) }\end{array}$ & 28 & 6.8 \\
\hline $\begin{array}{l}\text { Self-employed } \\
\text { (formal sector) }\end{array}$ & 17 & 4.1 \\
\hline Student & 24 & 5.8 \\
\hline Homemaker & 20 & 4.9 \\
\hline Retired/pensioner & 20 & 4.9 \\
\hline Disabled & 1 & 0.2 \\
\hline Refuse to answer & 1 & 0.2 \\
\hline \multicolumn{3}{|l|}{ Education level } \\
\hline Only primary & 10 & 2.4 \\
\hline Only secondary & 22 & 5.3 \\
\hline College & 68 & 16.5 \\
\hline University & 303 & 73.5 \\
\hline Other & 9 & 2.2 \\
\hline \multicolumn{3}{|l|}{ Water } \\
\hline Piped water (compound) & 407 & 98.8 \\
\hline Piped water (yard) & 2 & 0.5 \\
\hline Piped water (nearby) & 4 & 1.0 \\
\hline \multicolumn{3}{|l|}{ Electricity } \\
\hline Yes & 409 & 99.3 \\
\hline Refuse to answer & 3 & 0.7 \\
\hline \multicolumn{3}{|l|}{ Type of dwelling } \\
\hline Permanent & 409 & 99.3 \\
\hline
\end{tabular}

Page $6 / 17$ 


\begin{tabular}{|lll|}
\hline Variables & N & $\%$ \\
\hline Refuse to answer & 3 & 0.7 \\
\hline Toilet & & \\
\hline Yes & 410 & 99.5 \\
\hline No & 2 & 0.5 \\
\hline Self-reported health status & & \\
\hline Excellent & 10 & 2.4 \\
\hline Very good & 74 & 18.0 \\
\hline Good & 171 & 41.5 \\
\hline Fair & 137 & 33.3 \\
\hline Poor & 20 & 4.9 \\
\hline Chronic condition & & \\
\hline Yes & 45 & 10.9 \\
\hline No & 367 & 89.1 \\
\hline
\end{tabular}

The Fig. 2, shows the duration of affiliation with the PC facilities. The majority of the participants had been affiliated for 1-2 years. The median number of times that the users attended the clinic in the last 2-years was 4.0 (IQR: 3.0-6.0).

Table 3 shows the performance scores for each domain. The mean PC score was $2.64(S D=0.23)$ and the mean expanded PC score was $2.68(S D=0.19)$, implying a poor overall performance. The domains of first contact (utilisation), coordination (information), family-centredness and cultural competence had mean scores of 3.0 or more, suggesting an acceptable to good performance. All other domains had a mean score of less than 3.0 , suggesting a poor performance. The proportion of respondents giving an acceptable or good PC score for each domain are also shown in a radar chart in Fig. 3.

Table 3

Performance scores for KE-PCAT domains ( $\mathrm{N}=412)$

\begin{tabular}{|c|c|c|c|c|}
\hline \multirow[t]{2}{*}{ Domains } & \multicolumn{4}{|c|}{ Performance scores } \\
\hline & \multirow[t]{2}{*}{ Mean } & \multirow[t]{2}{*}{ SD } & \multirow{2}{*}{$\begin{array}{l}\text { Score }<3 \\
\mathrm{n}(\%)\end{array}$} & \multirow{2}{*}{$\begin{array}{l}\text { Score } \geq 3 \\
\mathrm{n}(\%)\end{array}$} \\
\hline & & & & \\
\hline First contact (utilisation) & 3.1 & 0.6 & $132(32.0)$ & $280(68.0)$ \\
\hline First contact (access) & 2.3 & 0.3 & $384(93.2)$ & $28(6.8)$ \\
\hline Ongoing care & 2.8 & 0.3 & $289(70.1)$ & $123(29.9)$ \\
\hline Coordination* & 2.9 & 0.5 & $12(2.9)$ & $5(1.2)$ \\
\hline Coordination & 3.0 & 0.5 & $174(42.2)$ & $238(57.8)$ \\
\hline \multicolumn{5}{|l|}{ (information) } \\
\hline Comprehensiveness & 2.1 & 0.3 & $403(97.8)$ & $9(2.2)$ \\
\hline \multicolumn{5}{|l|}{ (services available) } \\
\hline Comprehensiveness & 2.1 & 0.3 & 409 (99.3) & $3(0.7)$ \\
\hline \multicolumn{5}{|l|}{ (services provided) } \\
\hline Family-centredness & 3.1 & 0.6 & $143(34.7)$ & $269(65.3)$ \\
\hline Community orientation & 2.0 & 0.4 & $406(98.5)$ & $6(1.5)$ \\
\hline Culturally competent & 3.7 & 0.4 & $11(2.7)$ & 401 (97.3) \\
\hline Primary health care team & 2.1 & 0.6 & $336(81.6)$ & $76(18.4)$ \\
\hline Total primary care score & 2.6 & 0.2 & 387 (93.9) & $25(6.1)$ \\
\hline Expanded primary care score & 2.7 & 0.2 & $393(95.4)$ & $19(4.6)$ \\
\hline
\end{tabular}


Table 4 shows the associations between the socio-demographic characteristics of the users and the PC score. A borderline significant association was found between age groups and the PC score $(p=0.05)$. The post hoc analysis showed that the significance was due to a higher score amongst the $60-69$ year olds $(p=<0.0001)$, but all other age groups were not significantly. There was also an association between higher affiliation with the clinic and a higher PC score $(p=0.01)$.

Table 4

Relationship between the socio-demographic characteristics and the primary care performance score. $(\mathrm{N}=412)$

\begin{tabular}{|c|c|c|c|c|}
\hline Variables & $\begin{array}{l}\text { Score }<3 \\
\mathrm{n}(\%)\end{array}$ & $\begin{array}{l}\text { Score } \geq 3 \\
\mathrm{n}(\%)\end{array}$ & $\mathbf{N}$ & p-value \\
\hline Gender & & & & 0.25 \\
\hline Male & $171(92.4)$ & $14(7.6)$ & 185 & \\
\hline Female & $216(95.2)$ & $11(4.8)$ & 227 & \\
\hline Age Group & & & & 0.05 \\
\hline $20-29$ & $99(92.5)$ & $8(7.5)$ & 107 & \\
\hline $30-39$ & $168(95.5)$ & $8(4.5)$ & 176 & \\
\hline $40-49$ & $82(95.3)$ & $4(4.7)$ & 86 & \\
\hline $50-59$ & 34 (91.9) & $3(8.1)$ & 37 & \\
\hline $60-69$ & $4(66.7)$ & $2(33.3)$ & 6 & \\
\hline Employment & & & & 0.84 \\
\hline Employed-full time & $229(94.6)$ & $13(5.4)$ & 242 & \\
\hline Employed-part time & $54(91.5)$ & $5(8.5)$ & 59 & \\
\hline $\begin{array}{l}\text { Self-employed } \\
\text { (informal sector) }\end{array}$ & $27(96.4)$ & $1(3.6)$ & 28 & \\
\hline $\begin{array}{l}\text { Self-employed } \\
\text { (formal sector) }\end{array}$ & $16(94.1)$ & $1(5.9)$ & 17 & \\
\hline Student & $23(95.8)$ & $1(4.2)$ & 24 & \\
\hline Homemaker & $19(95.0)$ & $1(5.0)$ & 20 & \\
\hline Retired/pensioner & $17(85.0)$ & $3(15.0)$ & 20 & \\
\hline Disabled & $1(100.0)$ & $0(0.0)$ & 1 & \\
\hline Refuse to answer & $1(100.0)$ & $0(0.0)$ & 1 & \\
\hline Education & & & & 0.88 \\
\hline Primary & $10(100.0)$ & $0(0.0)$ & 10 & \\
\hline Secondary & $21(95.50$ & $1(4.5)$ & 22 & \\
\hline College & $64(94.1)$ & $4(5.9)$ & 68 & \\
\hline University & 284 (93.7) & $19(6.3)$ & 303 & \\
\hline Other & $8(88.9)$ & $1(11.1)$ & 9 & \\
\hline Users affiliation & & & & 0.01 \\
\hline Low & $65(100.0)$ & $0(0.0)$ & 65 & \\
\hline Moderate & 93 (97.9) & $2(2.1)$ & 95 & \\
\hline High & 229 (92.0) & $20(8.0)$ & 249 & \\
\hline
\end{tabular}

\section{Discussion}


In this private healthcare setting, the majority of the patients were young adults, female, employed, university graduates and resided in permanent dwellings. Most of them self-rated their health status as good and did not have chronic conditions.

Patients rated the clinics highly in terms of the information systems that helped to coordinate their care as well as in terms of the cultural competence and family-orientation of the GPs. On the other hand, they thought the clinics were not comprehensive in the range of services available and provided, and did not have a complete PHC team. There was little commitment to ongoing care, although patients also rarely had chronic conditions. Likewise, patients were rarely referred to the hospital and it was therefore difficult to assess coordination of care for such referrals. Despite high utilisation, the clinics were not always accessible at convenient times. The clinics did not have a community orientation and tended to focus only on the patients that attended the facilities. They did not have a well-defined geographic community or population at risk that they felt responsible for. Overall, the mean PC score and the mean expanded PC score implied an overall poor performance. Stronger affiliation to their clinic and higher PC scores were also associated.

Although our study showed a significant association between higher PC scores and elderly users, the patients were mostly young, employed and university graduates. The majority of users reported their health status to be good to excellent and did not have chronic conditions. These findings are similar to another study in the same clinics.(39)

The low prevalence of chronic conditions in this practice population could be due to the perception that GPs were not able to deal with certain chronic conditions and that it was better to attend family physicians or other specialists at the main hospital.(23)(38) Despite the presence of chronic illness, the health status may still be reported as good.(23) There was no relationship between self-rated health status and the PC score, although a study in Korea reported that a higher PC score had an association with better self-rated health status.(44)

First-contact access, which included the clinics' operational processes such as opening hours, telephonic access and the provision of emergency services after hours, was rated poor. This rating could have been influenced by the COVID-19 pandemic, county lock-down, and curfews leading to earlier closure of the clinics. In addition, telephonic consultations are not reimbursed by insurance companies in Kenya, unlike in high-income countries.(39)(45) A previous study carried out at these facilities showed high satisfaction with the clinics opening hours and waiting times, though concerns were expressed with the appointment system and easy access by phone to the GPs.(39)

Similar findings for access scores were reported in Canada (mean score 2.2), South Africa (mean score 2.5) and Malawi (mean score 2.8) showing that this aspect of care needs to be addressed in many PC systems.(22)(23)(46) In addition, several studies carried out across Africa in the public sector, reported low levels of patient satisfaction with access to PC, either due to inconvenient opening times and appointments, staff shortages or lack of emergency services after hours.(23)(47)(48)(49) On the other hand, private clinics in Vietnam, Hong Kong and China showed greater accessibility, attributed to a stronger culture of customer service.(50)(51)(52) Undoubtedly, difficulties in accessing PC can lead to inappropriate use of emergency services at the nearest hospital, where comprehensive care may not be so possible.(40)

First-contact utilisation scored highly, showing that patients tended to use the clinics when they had a health issue or needed a check-up. Such high utilisation might be due to the physical proximity of the clinics and satisfaction with the services offered, although such services were limited in scope.(39) (50)(53)

Although utilisation and long term affiliation was reported as good, the score for relational continuity and ongoing care was poor. The young and generally healthy practice population needed acute episodic care more than chronic care and may therefore not have formed strong relationships with their GPs. Poor continuity, however, is usually associated with more fragmented care and opportunities that are missed out for health promotion and disease prevention.(54)(55)

Other studies in this practice population have shown low expectations of the clinic services and little preference for a specific GP, although high confidence in the GPs ability to manage mostly minor acute problems in healthy young adults.(38)(39) Another reason for the gap in continuity, could be the lack of gate-keeping and availability of medical insurance cover, which allows patients to easily access the hospital specialists.(39)

The GPs have also been shown to lack person-centred communication skills, which are important for building relationships, fostering continuity and ensuring patient satisfaction, which impacts health outcomes.(39)(56)(57)(58). In addition, relational continuity may not be part of normative health seeking expectations in the Kenyan context, although it is normative in other health systems.(39)(59) High utilisation of the facilities and a good electronic medical record system did not translate into good continuity of care, although this has been shown elsewhere.(13)(22)(49)(50) Improving ongoing care will be important if these clinics become more comprehensive and manage more chronic conditions.

The patients rated the coordination of information systems as good, which is most likely due to the efficient and integrated electronic medical record system. Thus, the availability and transfer of information to facilitate patient's care could guide the development of an appropriate management plan.(23) (54)

However, users rated sequential coordination as barely acceptable, which indicated gaps in the transfer of information and care coordination between the PC facilities and the tertiary care hospital. This could be related to patient's being non-compliant to follow-up, lack of coordination between the GPs and the specialists, and limited relational continuity. In addition, easy access to specialist services at the hospital without the need for referral could also contribute to a low commitment to sequential coordination.(39) In many primary care systems, gatekeeping is obligatory in order to improve the efficiency and equity of the system, thereby making the coordination of care essential by the PC provider.(23)(38) However, an evaluation of GPs consultations in the same setting showed good parallel coordination between the different team members at the facility despite the low composition of the primary health care team. 
The provision of comprehensive services to meet the health needs of the community is a unique feature of PC in a generalist and undifferentiated environment. Comprehensiveness implies services across the whole burden of disease, the whole life courses and from health promotion to palliation.(23) In our study, patients rated comprehensiveness as poor. Primary care in low and middle income countries (LMICs) has historically been selective and driven by vertical disease-orientated programmes.(22)(23)(38)(50)(60) Even in high income countries such as Canada, comprehensive care is still an issue, despite having high relational continuity with providers.(46) In addition, the training of doctors in Kenya does not prepare them for comprehensive primary care.(58) Additional training in family medicine can narrow this gap.(35)(61) Comprehensive care plays a fundamental role in care continuity and when both are not delivered at an acceptable level it has implications for health outcomes.(23)(62)(63)

The low score for comprehensiveness may be related to services not being available or patients being unaware of services that could be offered by the GPs.(38) For example, patients have reported reduced confidence in the ability of the GPs' to manage and provide care related to screening for cervical cancer, antenatal care and end of life issues.(38) Services may not be provided by the GPs due to the availability of hospital specialists,(64) which in turn results in the GPs becoming deskilled.(58)(65) General practitioners may also lack certain skills to provide essential PC in specific areas of surgery, women's health, ear, nose and throat, ophthalmology and orthopaedics, which may result in increased overall costs and hospital visits.(58)(66)

Thinking from a family perspective, is one of the features of person-centred PC, that helps in understanding the patient's context.(67) Family-centredness was scored as acceptable to good. Several studies have related geographical proximity, family medical insurance cover, duration of affiliation, and high utilisation of PC, with higher family centredness.(38)(39)(49)(50)(68) On the other hand, evaluation of consultations in the same settings showed that the GPs did not explore the family and social context in more than half of the consultations.(58) Patients clearly felt that GPs were open to considering family in the consultations, although this was not borne out by actual observation of the consultations.(58)

Users rated community orientation as low. It is recognised that engagement in the community is not a strong point for the private sector.(5) The private sector generally focuses on the practice population, as individuals come for a service, as opposed to the public sector. In Kenya, particularly the public sector has prioritised community orientation in PHC service delivery.(20)(49)(50)(68) Despite the facilities being located in different communities throughout Nairobi, the organisation did not have a vision for monitoring and evaluation and health surveillance.(23)

Users rated cultural competence the highest, which implies that GPs were competent at handling the diversity of languages, contexts, health beliefs and values during their consultations.(69) This could be attributed to the GPs and other staff respecting the legitimacy of different cultures or because GPs actual shared the same language and cultural background as the patients.(13)(23)(49)(67) The need for cultural sensitivity in PHC was also highlighted in a study in Botswana.(70)

The users rated the composition of members of the primary health care team as low, which could be due to lack of awareness of the available services,(38) or gaps in access to a multidisciplinary team and comprehensive care.(38)(39) Despite the gap in the PC team, there was a high level of care coordination within the teams at the facilities. (Article 3, Chap. 3 in thesis) Many of the disciplines usually found in PC were actually located in the tertiary hospital, such as family medicine, social work, physiotherapy, dentistry and dietetics.(38)

\section{Strengths And Limitations}

This is a first-of-its-kind study to be carried out in Kenya in the private sector. The users' recall of their past experiences during health care visits may have created a recall bias, although research assistants were able to clarify and explore the answers to questions during the interviews. The possibility of an obsequiousness bias was also reduced by the use of unknown research assistants, assurance of anonymity and independence from the provision of care at the facility. The results cannot be generalised outside of the organisation, although might be similar in other private sector services that are organised along similar lines.

\section{Recommendations}

An improvement in the availability of routine services on weekends and after-office hours would add value to the already existing high user' utilisation with the facilities. The comprehensiveness of services and PC team need to be improved and marketed to the practice population, which should also improve continuity and coordination of care. Furthermore, creating awareness of the care package, formulating a system that encourages utilisation of PC, continuing professional development as well as workplace-based learning for GPs, could help in addressing the comprehensiveness of primary care.(71) Services can be offered more cost-effectively and conveniently in the PC clinics as opposed to the tertiary hospital. Deploying family physicians in these clinics, could go a long way in providing person-centred, continuous, coordinated and comprehensive care.

Consideration should be given to more community-orientated PC programs. Although this was a private sector organisation it was founded on a non-profit and philanthropic model that might be amenable to such a focus. This might also be achieved through public-private partnerships.(23)

The success of interventions to improve the domains that scored poorly can be monitored and evaluated by further evaluations using the PCAT in continuous quality improvement cycles.(23)

\section{Conclusion}

These primary care clinics in Nairobi had a poor overall PC score. There was a report of acceptable-to-good performance in first-contact utilisation, the information systems, family centredness and cultural competence. However, patients rated first-contact access, ongoing care, coordination of care, 
comprehensiveness of services, community orientation and availability of a complete primary health care team, as poor. The PC score could be improved by deploying family physicians to the clinics, increasing the scope of practice to become more comprehensive, improving access after-hours and marketing the use of the clinics to the practice population.

\section{Abbreviations}

AKUH Aga Khan University Hospital

COVID-19 Coronavirus Disease 2019

GPs General Practitioners

IQR Inter quantile Range

KE-PCAT Kenya-Primary Care Assessment Tool

LMICs Low and Middle Income Countries

NACOSTI National Commission for Science, Technology and Innovation

PC Primary Care

PCAT Primary Care Assessment Tool

PHC Primary Health Care

SD Standard Deviation

SPSS Statistical Package for Social Science

SSA Sub-Saharan Africa

UHC Universal Health Coverage

WHO World Health Organization

ZA PCAT South African Primary Care Assessment Tool

\section{Declarations}

We confirm that all methods were performed in accordance with the relevant guidelines and regulations.

\section{Ethics approval and consent to participate}

The study was ethically approved by the National Commission for Science, Technology \& Innovation Research, Kenya-License no: NACOSTI/P/20/7046, the Research and Ethics Committee of the Aga Khan University Hospital, Nairobi -reference no: 2020/IERC-119 [v2] and the Stellenbosch University Health Research Ethics Committee-reference no: S20/07/167. We confirm that informed consent was obtained from all the participants.

\section{Consent for publication}

Not applicable

\section{Availability of data and materials}

The authors confirm that the data supporting the findings of this study are available on reasonable request to the authors.

\section{Competing interests}

The authors declare that they have no competing interests.

\section{Funding}

The researcher received no specific grant from any funding agency in the public, commercial or not-for-profit sectors.

\section{Authors' contributions}

GM is the principle investigator of this study and assumed primary responsibility of conceptualising, writing the proposal, validating the tool, collecting data, analysing the data and reporting the data. RM provided guidance and supervision for the conceptualisation of the study, validation of the tool, analysis, reporting and approved the final manuscript. 


\section{Disclaimer}

The views and opinions expressed in this article are those of the authors, and do not necessarily reflect the official policy or position of any affiliated agencies of the authors.

\section{Acknowledgements}

I wish to acknowledge and thank the following who have played invaluable roles in this study. I am sincerely grateful to Dr Graham Bresick for the approval for the use of the Primary Care Assessment Tool and to my Kenyan family physicians and colleagues from the various Universities in Kenya for assisting with the validation of the PCAT in the Kenyan context.

My appreciation goes to: Mr James Orwa; managers and staff of all the primary care clinics for assistance with the research and for permitting the data collection. Sincere appreciation to Dr Gibran Merali for his ICT wizardry, Mohamoud Merali for proof reading and the research assistants - Dr Zeenia Merali and Lilian Ndirangu.

\section{Authors' information (optional)}

Dr Gulnaz Mohamoud is a Senior lecturer in the Department of Family Medicine at the Aga Khan University Hospital in Nairobi, Kenya. She has carried out and published several research studies in the area of primary care in Kenya. She continues to contribute towards improving the recognition and understanding of family medicine in Kenya.

Professor Robert Mash is the Head of the Division of Family Medicine and Primary Care at Stellenbosch University in South Africa. Professor Mash is coordinator of the Primary Care and Family Medicine (Primafamed) network in SSA and Chair of the global Primary Health Care Research Consortium.

\section{References}

1. WHO. The World Health Report 2008: Primary Health Care: Now More Than Ever [Internet]. The World Health Report. 2008 [cited 2020 Mar 3]. p. 148. Available from: http://www.who.int/whr/2008/en/

2. Hone T, Macinko J, Millett C. Revisiting Alma-Ata: what is the role of primary health care in achieving the Sustainable Development Goals? Lancet. 2018 Oct 20;392(10156):1461-72.

3. Peiris D, Sharma M, Praveen D, Bitton A, Bresick G, Coffman M, et al. Strengthening primary health care in the COVID-19 era: a review of best practices to inform health system responses in low- and middle-income countries. WHO South-East Asia J Public Heal. 2021;10(3):6.

4. WHO; UNICEF. Declaration of Astana [Internet]. Global Conference on Primary Health Care. 2018 [cited 2020 Jul 21]. p. 1-12. Available from: https://www.who.int/primary-health/conference-phc

5. Langlois E V., McKenzie A, Schneider H, Mecaskey JW. Measures to strengthen primary health-care systems in low-and middle-income countries. Bull World Health Organ [Internet]. 2020 [cited 2021 Apr 20];98:781-91. Available from: https://10.0.9.167/BLT.20.252742

6. De Maeseneer J, Flinkenflögel M. Primary health care in Africa: Do family physicians fit in? Br J Gen Pract [Internet]. 2010;60(573):286-92. Available from: 10.3399/bjgp10X483977

7. Hogg W, Dahrouge S, Russell G, Tuna M, Geneau R, Muldoon L, et al. Health promotion activity in primary care: Performance of models and associated factors. Open Med. 2009;3(3):165-73.

8. WHO. Closing the gap in a generation: Final Report. [Internet]. 2008 [cited 2020 Apr 15]. Available from: https://www.who.int/social_determinants/final_report/csdh_finalreport_2008.pdf

9. Mash R, Howe A, Olayemi O, Makwero M, Ray S, Zerihun M, et al. Reflections on family medicine and primary healthcare in sub- Saharan Africa. BMJ Glob Heal [Internet]. 2018;3(e000662):1-3. Available from: 10.1136/bmjgh-2017-000662

10. WHO, Unicef. Operational framework for primary health care: Trasforming vision into action [Internet]. 2020 [cited 2021 Jan 14]. Available from: https://apps.who.int/iris/handle/10665/337641

11. Guthrie B, Dreischulte T. Quality in primary care. BMJ. 2014;349:1-36.

12. Maher D, Smeeth L, Sekajugo J. Health transition in Africa: Practical policy proposals for primary care. Bull World Health Organ [Internet]. 2010 [cited 2020 Mar 10];88(12):943-8. Available from: https://www.ncbi.nlm.nih.gov/pmc/articles/PMC2995191/

13. Bresick G, von Pressentin KB, Mash R. Evaluating the performance of South African primary care: a cross-sectional descriptive survey. South African Fam Pract. 2019;61(3):109-16.

14. Mash R, Downing R, Moosa S, De Maeseneer J. Exploring the key principles of family medicine in sub-Saharan Africa: International Delphi consensus process. South African Fam Pract. 2008;50(3):60-5.

15. World Health Organization (WHO). PHCPI Primary Health Care Improvement Global Stakeholder Meeting 6 April Workshop : Shaping Primary Health Care [Internet]. 2015 [cited 2020 Jan 6]. Available from: https://www.who.int/servicedeliverysafety/events/6_April_Agenda.pdf?ua=1

16. De Maeseneer J, Li D, Palsdottir B, Mash B, Aarendonk D, Stavdal A, et al. Universal health coverage and primary health care: The 30 by 2030 campaign. Bull World Health Organ [Internet]. 2020 [cited 2021 Mar 20];98(11):812-4. Available from:

https://www.ncbi.nlm.nih.gov/pmc/articles/PMC7607468/pdf/BLT.19.245670.pdf 
17. Agyepong IA, Sewankambo N, Binagwaho A, Coll-Seck AM, Corrah T, Ezeh A, et al. The path to longer and healthier lives for all Africans by 2030 : the Lancet Commission on the future of health in sub-Saharan Africa. Lancet. 2017;390(10114):2803-59.

18. Goodyear-Smith F, Kinder K, Mannie C, Strydom S, Bazemore A, Phillips RL. Relationship between the perceived strength of countries' primary care system and COVID-19 mortality: an international survey study. BJGP Open. 2020;4(4):1-13.

19. Delivering Primary Health Services in Devolved Health Systems of Kenya Challenges and Opportunities Final Report [Internet]. 2014 [cited 2018 Dec 23]. Available from: http://documents.worldbank.org/curated/en/201501468277739155/pdf/922640WP0P14870es0and00pportunities.pdf

20. MOH. Kenya Health Policy 2014-2030. Oxford J [Internet]. 2014 [cited 2019 Apr 12];XXXIII(2):81-7. Available from: http://www.americanbanker.com/issues/179_124/which-city-is-the-next-big-fintech-hub-new-york-stakes-its-claim-10683451.html\%5Cnhttp://www.ncbi.nlm.nih.gov/pubmed/15003161\%5Cnhttp://cid.oxfordjournals.org/lookup/doi/10.1093/cid/cir991\%5Cnhttp://www.scielo

21. Ponka D, Rouleau K, Arya N, Redwood-Campbell L, Woollard R, Siedlecki B, et al. Developing the evidentiary basis for family medicine in the global context The Besrour Papers: a series on the state of family medicine in the world. Can Fam Physician [Internet]. 2015 [cited 2018 Dec 23];61:596-600. Available from: http://www.cfp.ca/content/cfp/61/7/596.full.pdf

22. Dullie L, Meland E, Mildestvedt T, Hetlevik $\varnothing$, Gjesdal S. Quality of primary care from patients' perspective: A cross sectional study of outpatients' experience in public health facilities in rural Malawi. BMC Health Serv Res. 2018;18(1):1-9.

23. Bresick GF, Sayed A-R, Le Grange C, Bhagwan S, Manga N, Hellenberg D. Western Cape Primary Care Assessment Tool (PCAT) study: Measuring primary care organisation and performance in the Western Cape Province, South Africa (2013). African J Prim Heal care Fam Med. 2016 May;8(1):e112.

24. Kringos D, Nuti S, Anastasy C, Barry M, Murauskiene L, Siciliani L, et al. Re-thinking performance assessment for primary care: Opinion of the expert panel on effective ways of investing in health. Eur J Gen Pract. 2019 Jan 2;25(1):55-61.

25. Veillard J, Cowling K, Bitton A, Ratcliffe H, Kimball M, Barkley S, et al. Better Measurement for Performance Improvement in Low- and Middle-Income Countries: The Primary Health Care Performance Initiative (PHCPI) Experience of Conceptual Framework Development and Indicator Selection. Milbank Q. 2017;95(4):836-83.

26. Shi L, Starfield B, Xu J. Validating the adult primary care assessment tool. J Fam Pract [Internet]. 2001 [cited 2021 Mar 4];50(2):161-75. Available from: http://go.galegroup.com/ps/i.do?

id=GALE\%257CA71403442\&sid=googleScholar\&v=2.1\&it=r\&linkaccess=fulltext\&issn=00943509\&p=AONE\&sw=W

27. Starfield B, Shi L, Macinko J. Contribution of primary care to health systems and health. Milbank Q [Internet]. 2005 [cited 2019 Dec 23$] ; 83(3): 457-502$. Available from: http://www.ncbi.nlm.nih.gov/pubmed/16202000

28. Bresick G, Christians F, Makwero M, Besigye I, Malope S, Dullie L. Primary health care performance: a scoping review of the current state of measurement in Africa. BMJ Glob Heal. 2019;4(Suppl 8):e001496.

29. Li X, Krumholz HM, Yip W, Cheng KK, Maeseneer J De, Meng Q, et al. Quality of primary health care in China : challenges and recommendations. Lancet. 2020;395:1802-12.

30. Shi L, Starfield B, Politzer R, Regan J. Primary care, self-rated health, and reductions in social disparities in health. Health Serv Res. 2002;37(3):529-50.

31. Allianz Care. Healthcare in Kenya- Support [Internet]. 2020 [cited 2020 May 9]. Available from: https://www.allianzworldwidecare.com/en/support/view/national-healthcaresystems/\%0Ahealthcare-in-kenya/

32. American Academy of Family Physician. Definition of Family Medicine [Internet]. 2016 [cited 2019 Nov 9]. Available from: https://www.aafp.org/about/policies/all/family-medicine-definition.html

33. De Maeseneer J, Flinkenflögel M. Primary health care in Africa: Do family physicians fit in? Br J Gen Pract [Internet]. 2010 [cited 2019 Jun 12];60(573):286-92. Available from: https://bjgp.org/content/bjgp/60/573/286.full.pdf

34. Mash R, Von Pressentin K. Strengthening the district health system through family physicians [Internet]. South African Health Review. 2018. p. 33-9. Available from: https://saafp.org/2018/12/18/20181218-sa-health-review-chapter-strengthening-the-district-health-system-through-family-physicians/

35. Mohamed KG, Hunskaar S, Abdelrahman SH, Malik EM. Scaling up family medicine training in Gezira, Sudan - a 2-year in-service master programme using modern information and communication technology: A survey study. Hum Resour Health [Internet]. 2014 [cited 2021 Feb 10];12(1):1-9. Available from: https://human-resources-health.biomedcentral.com/articles/10.1186/1478-4491-12-3

36. Momanyi K, Dinant GJ, Bouwmans M, Jaarsma S, Chege P. Current status of family medicine in Kenya; family physicians' perception of their role. African J Prim Heal Care Fam Med. 2020;12(1):1-4.

37. Morgan R, Ensor T, Waters H. Performance of private sector health care: implications for universal health coverage. Lancet. 2016;388(10044):606-12.

38. Mohamoud G, Mash B, Merali M, Orwa J, Mahoney M. Perceptions regarding the scope of practice of family doctors amongst patients in primary care settings in Nairobi. African J Prim Heal care \&amp; Fam Med. 2018;10(1).

39. Mohamoud G, Mash R. Evaluation of the quality of service delivery in private sector, primary care clinics in Kenya: A descriptive patient survey. South African Fam Pract. 2020;62(1).

40. Bresick G, von Pressentin KB, Mash R. Evaluating the performance of South African primary care: a cross-sectional descriptive survey. South African Fam Pract [Internet]. 2019 [cited 2021 Jan 14];61(3):109-16. Available from: https://doi.org/10.1080/20786190.2019.1596666

41. Sayed A, Bresick G, Bhagwan S, Manga C. Adaptation and cross-cultural validation of the United States primary care assessment tool (expanded version) for use in South Africa. African J Prim Heal Care Fam Med. 2015;7. 
42. Bresick G, Christians F, Makwero M, Besigye I, Malope S, Dullie L. Primary health care performance: a scoping review of the current state of measurement in Africa. BMJ Glob Heal. 2019;4(Suppl 8):e001496.

43. John Hopkins University. Primary care assessment tools [Internet]. [cited 2016 Dec 10]. Available from: https://www.jhsph.edu/research/centers-andinstitutes/johns-hopkins-primary-care-policy-center/pca_tools.html

44. Sung NJ, Markuns JF, Park KH, Kim K, Lee H, Lee JH. Higher quality primary care is associated with good self-rated health status. Fam Pract. 2013;30(5):568-75.

45. Foster J, Jessopp L, Dale J. Concerns and confidence of general practitioners in providing telephone consultations. Br J Gen Pract. 1999;49(439):1113.

46. Haggerty JL, Pineault R, Beaulieu MD, Brunelle Y, Gauthier J, Goulet F, et al. Room for improvement: Patients' experiences of primary care in Quebec before major reforms. Can Fam Physician. 2007;53(6):1056-7.

47. Dullie L, Meland E, Hetlevik $\emptyset$, Mildestvedt T, Gjesdal S. Development and validation of a Malawian version of the primary care assessment tool. BMC Fam Pract. 2018;19(1):1-11.

48. Ogunfowokan O, Mora M. Time, expectation and satisfaction: Patients' experience at National Hospital Abuja, Nigeria. phcfm [Internet]. 2012 [cited 2021 Jan 20];4(1):6. Available from: http://dx.doi.org/10.4102/

49. Mukiapini S, Bresick G, Sayed AR, Le Grange C. Baseline measures of primary health care team functioning and overall primary health care performance at Du Noon Community Health Centre. African J Prim Heal Care Fam Med. 2018;10(1):1-11.

50. Hoa NT, Tam NM, Derese A, Markuns JF, Peersman W. Patient experiences of primary care quality amongst different types of health care facilities in central Vietnam. BMC Health Serv Res. 2019;19(1):1-11.

51. Wong SY, Kung K, Griffiths SM, Carthy T, Wong MC, Lo S V., et al. Comparison of primary care experiences among adults in general outpatient clinics and private general practice clinics in Hong Kong. BMC Public Health. 2010;10.

52. Feng S, Shi L, Zeng J, Chen W, Ling L. Comparison of primary care experiences in village clinics with different ownership models in guangdong province, China. PLoS One. 2017;12(1):1-15.

53. Jung H-M, Jo M-W, Kim H-J, Jang W-M, Lee J-Y, Eun S-J. The Primary Care Performance of Three Types of Medical Institutions: A Public Survey using the Korean Primary Care Assessment Tool. Qual Improv Heal Care [Internet]. 2019 [cited 2020 Mar 12];25(2):16-25. Available from: http://dx.doi.org/10.14371/QIH.2019.25.2.16

54. Bresick G, Sayed A-. R, Grange C, Bhagwan S, Manga N, Hellenberg D. Western Cape Primary Care Assessment Tool (PCAT) study: Measuring primary care organisation and performance in the Western Cape Province, South Africa (2013). African J Prim Heal Care Fam Med. 2013;8:1-43.

55. Haggerty JL, Reid RJ, Freeman GK, Starfield BH, Adair CE, McKendry R. Continuity of care: a multidisciplinary review. BMJ [Internet]. 2003 [cited 2019 Oct 10];327(7425):1219-21. Available from: https://doi.org/10.1136/bmj.327.7425.1219

56. Price M, Lau FY. Provider connectedness and communication patterns: Extending continuity of care in the context of the circle of care. BMC Health Serv Res. 2013;13(1).

57. Stebbins GT, Gabrieli JDE, Shannon KM, Penn RD, Goetz CG. Intention to discontinue care among primary care patients: Influence of physician behavior and process of care. J Gen Intern Med. 2001;16(10):668-74.

58. Mohamoud G. An evaluation of the quality of service delivery in primary care facilities in the private sector in Nairobi, Kenya. [Internet]. Cape Town: SUNScholar; 2021.271 p. Available from: https://scholar.sun.ac.za

59. Wetmore S, Ccfp M, Leslie F, Mpa B, Graham E, Susan RN, et al. Patient satisfaction with access and continuity of care in a multidisciplinary academic family medicine clinic. Can Fam Physician. 2014;60:230-6.

60. Macinko J, Almeida C, De Sá PK. A rapid assessment methodology for the evaluation of primary care organization and performance in Brazil. Health Policy Plan. 2007;22(3):167-77.

61. Mash R. Strengthening the district health system through family physicians [Internet]. Vol. 2018, South African Health Review. 2018 [cited 2019 Apr 12]. p. 33-9. Available from: https://journals.co.za/docserver/fulltext/healthr_2018_a6.pdf? expires=1589473629\&id=id\&accname=guest \&checksum=D3A06A84490D4F865DC3701261CFE463

62. Draper CA, Draper CE, Bresick GF. Alignment between Chronic Disease Policy and Practice: Case Study at a Primary Care Facility. PLoS One [Internet]. 2014 [cited 2019 Oct 10];9(8):1-8. Available from: www.plosone.org

63. Haggerty JL, Reid RJ, Freeman GK, Starfield BH, Adair CE, McKendry R. Continuity of care: a multidisciplinary review. BMJ. 2003 Nov;327(7425):121921.

64. Mash R, Almeida M, Wong WCW, Kumar R, Pressentin KB Von. The roles and training of primary care doctors : China, India, Brazil and South Africa. Hum Resour Health [Internet]. 2015 [cited 2019 Apr 20];13(93):1-9. Available from: http://dx.doi.org/10.1186/s12960-015-0090-7

65. Mitsuyama T, Son D, Eto M. Competencies required for general practitioners/family physicians in urban areas versus non-urban areas: A preliminary study. BMC Fam Pract. 2018;19(1):1-9.

66. Huddlestone L, Walker GM, Hussain-Mills R, Ratschen E. Treating tobacco dependence in older adults: a survey of primary care clinicians' knowledge, attitudes, and practice. BMC Fam Pract [Internet]. 2015 [cited 2020 Mar 14];16(1). Available from: http://dx.doi.org/10.1186/s12875-015-0317-7

67. Mash B. Handbook of Family Medicine. Cape Town: Oxford University Press Southern Africa; 2006. 
68. Macinko J, Almeida C, Klingelhoefer P, Sa'3 S. A rapid assessment methodology for the evaluation of primary care organization and performance in Brazil. Health Policy Plan [Internet]. 2007 [cited 2020 Mar 13];22:167-77. Available from: https://academic.oup.com/heapol/article/22/3/167/632712 69. Swartz L. The virtues of feeling culturally incompetent. Monash Bioeth Rev. 2007;26(4):36-46.

70. Setlhare V, Couper I, Wright A. Patient-centredness: Meaning and propriety in the Botswana, African and non-Western contexts. African J Prim Heal Care Fam Med. 2014;6(1):4-7.

71. Claramita M, Ekawati FM, Gayatri A, Istiono W, Sutomo AH, Kusnanto H, et al. Preparatory graduate professional training in general practice by using the "experiential learning" framework. Asia Pac Fam Med [Internet]. 2018 [cited 2020 May 12];17(1):1-13. Available from:

https://doi.org/10.1186/s12930-018-0042-1

\section{Figures}

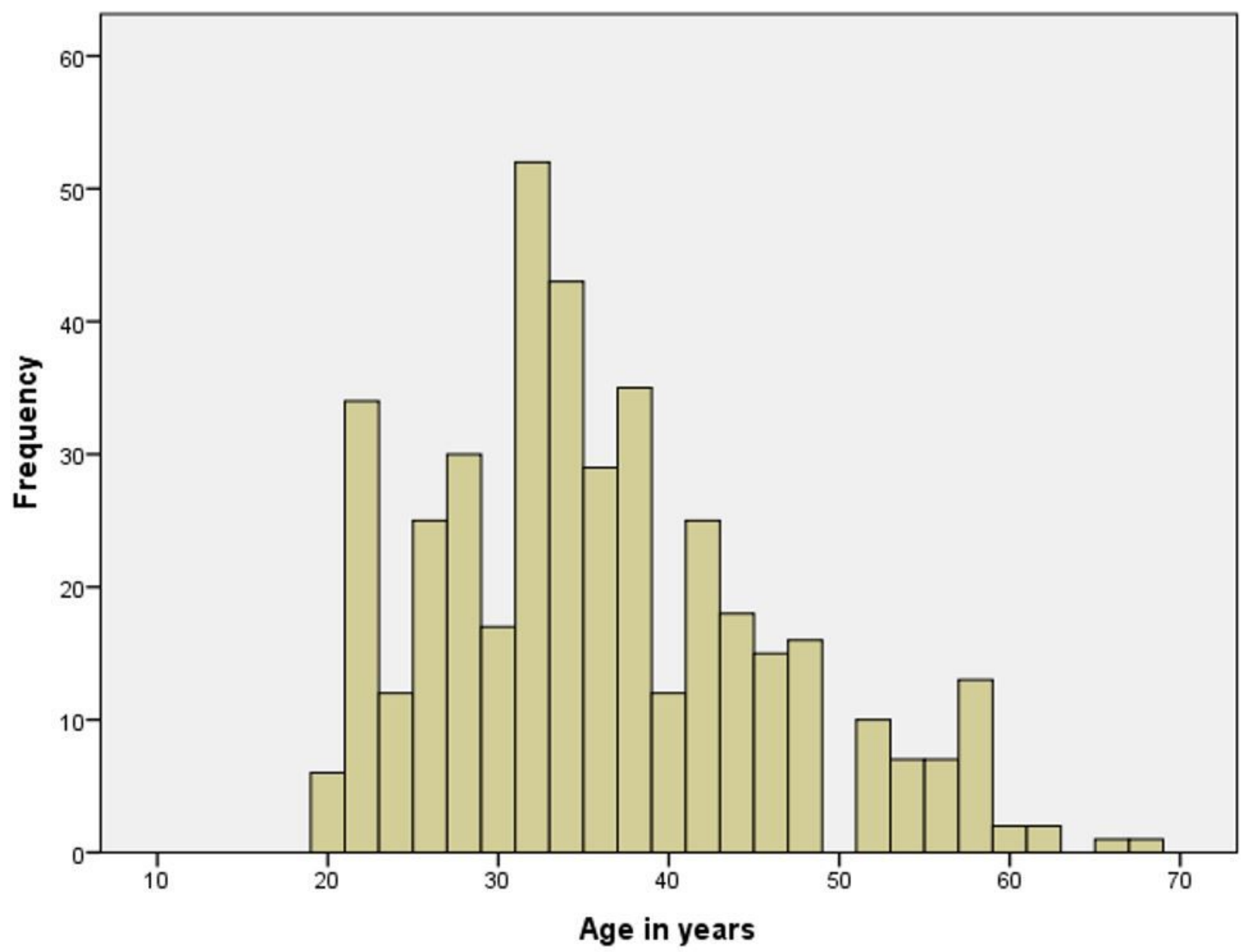

Figure 1

Age distribution of the participants. 


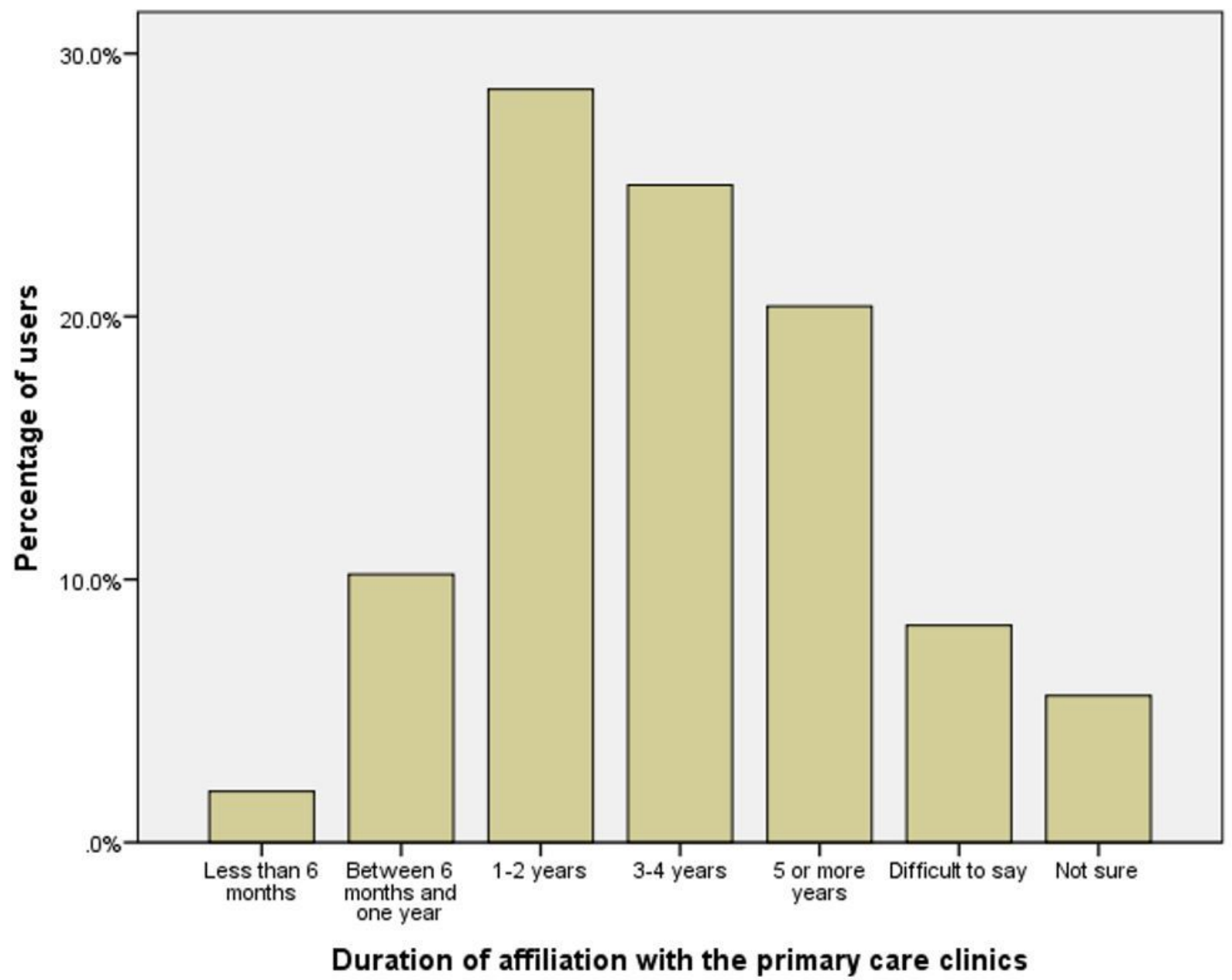

Figure 2

Users' affiliation with the primary care clinics. 


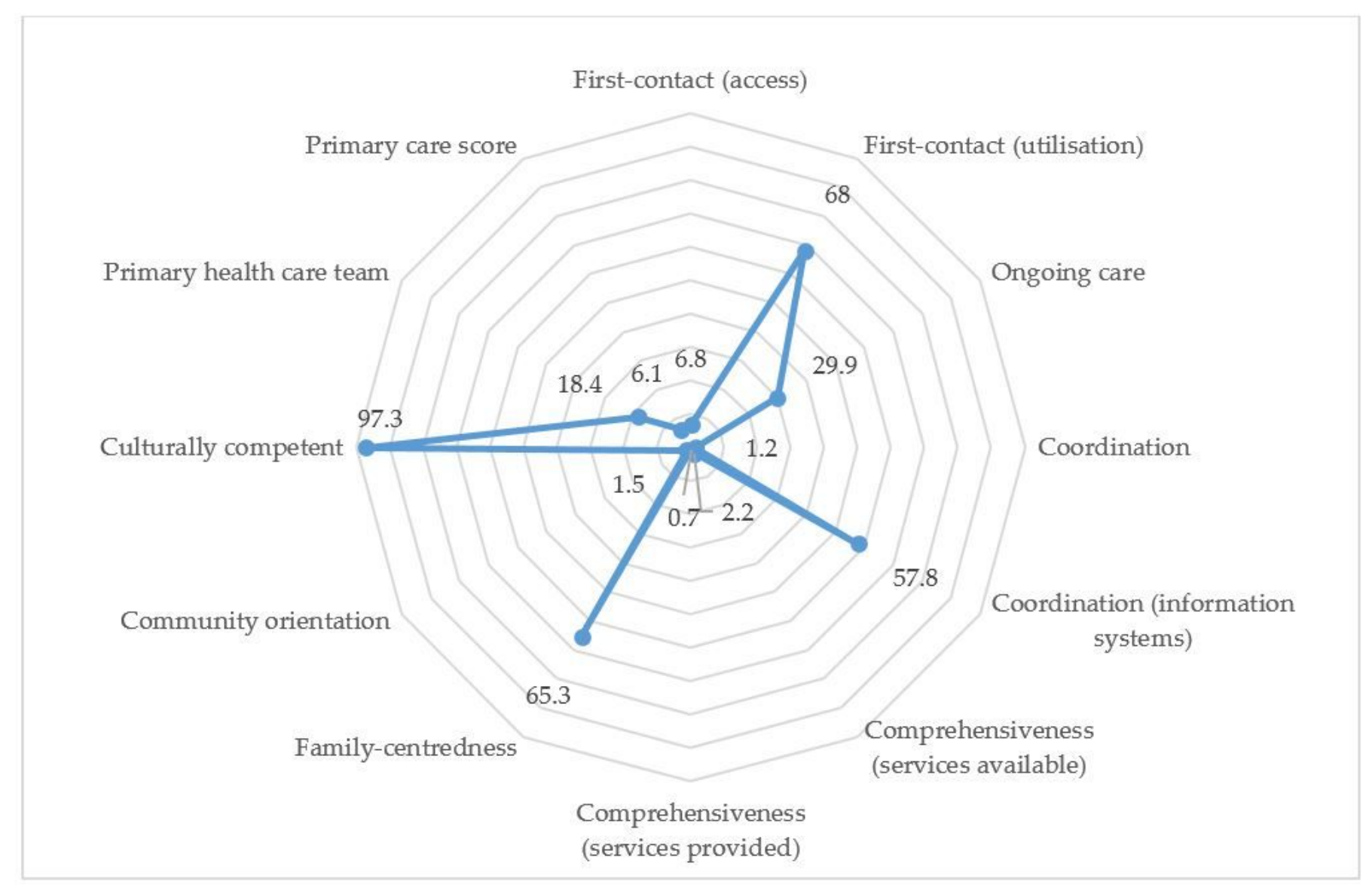

Figure 3

Proportion of respondents evaluating each domain as acceptable to good 